\title{
Strategies for development of clean energy in China
}

\author{
Yang Zhen * and Zhang Hongliang \\ Department of Environmental Sciences and Engineering, Tsinghua University, Beijing 100084, China
}

\begin{abstract}
A development framework of clean energy in China is put forward based on core development strategy, technology support, and policy and laws support. In this framework, the priority development and strategic backup of clean energy are defined, and the technology support and policy and laws support are also presented.
\end{abstract}

Key words: China, clean energy, strategy framework

\section{Introduction}

Energy is one of the most sensitive problems for the sustainable development of society and economy worldwide. The rapid economic development of the world, especially in developing countries, is mostly based on the consumption of fossil fuel such as coal, oil, and natural gas. As a result, the large emission of $\mathrm{CO}_{2}, \mathrm{NO}_{x}$ and other kinds of gases has caused a great many problems such as global warming, thawing of polar ice cap and plateau permafrost, rise of sea level and frequent climatic disasters, as well as severe environmental accidents such as acid rain and water pollution caused by $\mathrm{SO}_{2}$ and dust. The development of clean energy can reduce the emission of greenhouse gases and other pollutants, and can help to improve the global environments (Pan, 1997; Zhang, 2004; Su et al, 2006). Based on an analysis of current situation and problems in clean energy development in China, this paper establishes a strategic framework for clean energy development in China with the expectation that it would provide some theoretical and practical guidance.

\section{Current situation and problems in clean energy development in China}

\subsection{Current situation}

Under the circumstances of reduction of greenhouse gas emission and conventional fossil energy crisis, clean energy has been developed significantly as a part of national strategy of China. In 2005, the renewable energy consumed in China reached 1.4 hundred million tonnes of oil equivalent (toe) and accounted for $7 \%$ of the total energy consumption, of which hydropower was 1.08 hundred million $\mathrm{kW}$, accounting for $25 \%$ of the total electricity generation capacity, and the total generated electricity of the hydropower was 400 billion

\footnotetext{
* Corresponding author. E-mail: yangz04@mails.tsinghua.edu.cn Received December 20, 2007
}

$\mathrm{kWh}$; the solar water heaters was 75 million $\mathrm{m}^{2}$, saving 1,125 tonnes of coal equivalent (tce) or electricity of 35 billion $\mathrm{kWh}$; the production of the solar cells was 1.5 hundred thousand $\mathrm{kW}$, and the total installed capacity of PV power station was 70 thousand $\mathrm{kW}$; the total installed wind farm capacity of 1,869 generators was 1.26 million $\mathrm{kW}$; and annual methane production was 6.5 billion $\mathrm{m}^{3}$ and annual ethanol production was 1.02 million tons (Yu, 2006). The research and development of nuclear energy in China can be traced back to the 1960s, and now five nuclear power stations named Qinshan I Nuclear Power Plant, Qinshan II Nuclear Power Plant, Qinshan III Nuclear Power Plant, Dayawan Nuclear Power Station and Ling'ao Nuclear Power Station (Phase I) have been built and another two are under construction, namely Tianwan Nuclear Power Station (Phase I) and Ling' ao Nuclear Power Station (Phase II) (Zhai et al, 2005; Yuan et al, 2005). As a common clean energy, bio-energy is evidently superior and household methane is popularized rapidly with the maturation of the related technologies $(\mathrm{He}, 2007)$. Till the end of 2005, 17.51 million families have built methane pool, which increased the rural energy utilization efficiency to over $30 \%$ and $50 \%$ of which is high-quality energy, bringing great economic benefit, ecological benefit and social benefit, but some scientific and technological problems of efficient methane fermentation have to be resolved (Feng et al, 2005b).

\subsection{Existing problems}

There is consensus in China on energy strategy to develop clean energy, but there still exist some problems to be resolved.

1) Lack of markets for clean energy. Although it is widely recognized that clean energy has good prospects, lack of markets is always a problem for its development. Due to technical and cost problems, clean energy is currently still the supplementary energy, far from being the mainstream of energy development. There is a long way to go for clean energy to enter into public life. Compared with the price of conventional energy such as coal, oil, and natural gas, the 
price of clean energy does not have the advantage for getting into the market.

2) Lack of awareness of clean energy. Undoubtedly, a good social atmosphere is necessary for the healthy and rapid development of clean energy. Currently, although the academic voice for using clean energy is relatively high, the public knowledge of clean energy is not adequate. What is more, the negative attitude of some decision makers also affects the development of clean energy to some extent.

3) Lack of policy support for developing clean energy. As a new industry, clean energy needs support of governments at all levels in policies, taxes, related laws and regulations at the research and popularization stages. But the local governments do not have enough experience in making decision concerning clean energy, which causes a lack of policy support and hence affects the development of clean energy.

4) The clean energy technologies need further development. Compared with some mature clean energy technologies, e.g., clean coal, most clean energy technologies can not be utilized widely, the main reason is their relatively high cost. Lack of economic feasibility is the obstacle for clean energy development.

The existing plan for clean energy lacks comprehensive, scientific and feasible supports of technology, policy and law. Although some clean energy-related policies and laws have been promulgated in China, there is a lack of a framework of strategy, technology and assistance as well as an unambiguous plan for such fields as priority development, key support and strategic backup. Therefore, it is necessary to establish a development framework of clean energy consisting of core development, supporting technologies, policies and laws.

\section{Establishment of framework for clean energy development in China}

To establish a strategic framework for clean energy development, three aspects should be taken into account, namely, core development fields of clean energy, key technology support and policy and law support guarantee. For core development fields of clean energy, the priority development fields and the mid- and long-term strategic and technical backup should be specified. For key technology support, the research emphasis on key technologies and related technical backup should be made according to the ranking of the development priority of different clean energy fields. As soft environments, policies and laws play an important role in the development of a new industry. Fig. 1 is the strategic framework for clean energy development in China.

\subsection{Core fields of clean energy development in China}

There are eight types of clean energy in China, i.e. conventional energy, nuclear energy, hydropower, geothermal

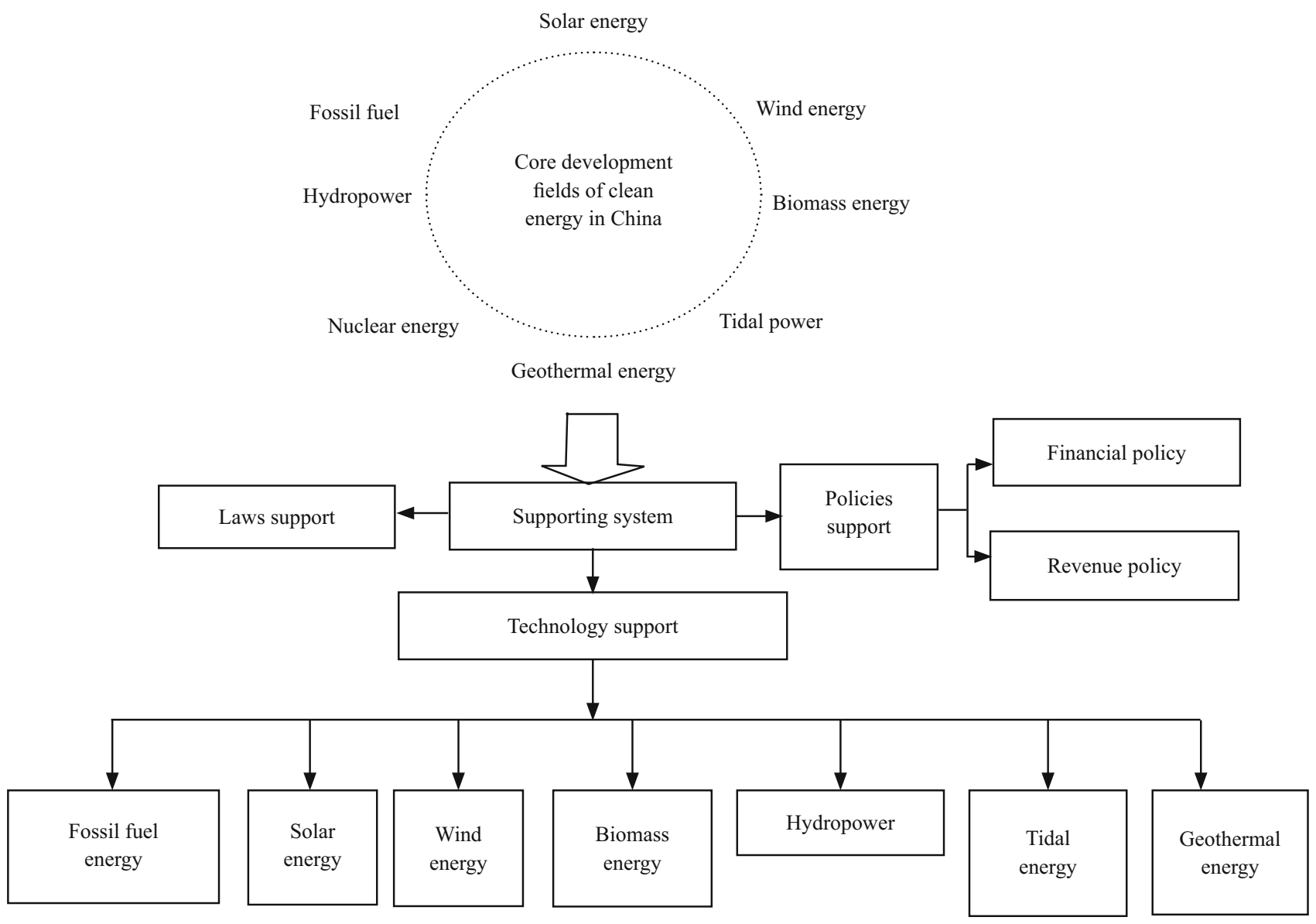

Fig. 1 Strategic framework for clean energy development in China 
energy, tidal power, biomass energy, wind energy and solar energy. Each one has its unique potentialities and advantages for development, but there exists an extreme imbalance among them from the perspectives of economic growth, energy security, reduction of greenhouse gas emission and related technologies. Conventional energy, such as coal, oil and natural gas, is dominant in boosting economic growth of China and will not be replaced by other types of energy in a long time, so clean usage of conventional energy based on recycling economy is the best choice currently for economic growth, energy security and environment protection. From the technical point of view, hydropower and nuclear energy could be developed for use in a large scale but it also might cause some environmental problems such as environmental impact near large reservoir and the problems of nuclear leakage. Biomass energy, which is an important strategic backup of energy resource in China, is developed best compared with other types of clean energy, owing to its large resource potentiality and broad development prospect, but there still exist some technical and environmental obstacles for its large scale development. Geothermal energy, tidal power, wind energy and solar energy have already been used in some fields but so far they can not replace conventional energy or become the main energy source in China, so more support should be provided in foundational research, technological development and popularization.

Therefore, the core fields of clean energy development in China can be divided into priority development field and strategic backup field according to the targets of national economy, environmental protection and energy security. Conventional energy, including coal, oil and natural gas, should be classified as a priority development field. Various types of clean energy, such as nuclear energy, hydropower, geothermal energy, tidal power, biomass energy, wind energy and solar energy could be classified as alternate energy and with the development of the related basic theories and technologies, they would be treated as strategic energy backup. According to resource distribution and non-balanced development strategy, wind energy, solar energy and biomass energy could be selected as the main renewable energy resources.

\subsubsection{Priority development of conventional energy}

Although a lot of pollutants such as $\mathrm{CO}_{2}, \mathrm{NO}_{x}, \mathrm{SO}_{2}$ and dusts are emitted to the environment during consumption of conventional energy including coal, oil and natural gas, for a very long time these energy will still be the main energy sources supporting economy growth, hence, reducing the problems of environmental pollution through technical innovation and change of utilization model of conventional energy is now most important and urgent. The eleventh Five-Year-Plan on energy proposes energysaving and consumption-reducing strategies, providing a strategic guideline to reducing problems of environmental pollution. Establishment of technical innovation system for conventional energy is a very effective way to environment protection and efficient utilization of energy.

\subsubsection{Development of alternate energy}

Nuclear energy, hydropower, geothermal energy, tidal power, biomass energy, wind energy and solar energy do not emit pollutants such as $\mathrm{CO}_{2}, \mathrm{NO}_{x}, \mathrm{SO}_{2}$ and dusts during their consumption, hence do not result in environmental pollution except for the radiation risk of nuclear energy, so they are classified as clean energy. The regional development strategy of clean energy in China is suggested and described as follows according to the characteristics of clean energy resources in different regions.

\section{1) Regional development strategy for wind energy}

China has extremely abundant wind energy resources. One percent of the total area of China has a wind speed higher than $6 \mathrm{~m} / \mathrm{s}$, and the wind energy resources are mainly distributed in southern and eastern coastal regions and islands, including the Shandong province, Liaodong peninsula in the south of northeast China, shore of the Yellow Sea, shore of the South China Sea, Hainan province and islands in the South China Sea, the region from northern Yinshan mountains to northern Daxinganling mountains in the Inner Mongolia Autonomous Region, Dabancheng and Alashankou of the Xinjiang Autonomous Region, Hexi Corridor in the Gansu province, downstream of Songhuajiang River in the Heilongjiang province, northern Zhangjiakou region in the Hebei province, and mountain tops and mountain passes in many places. The total reserves of wind energy are estimated as high as 3.226 billion $\mathrm{kW}$, of which about $2.53 \times 10^{8} \mathrm{~kW}$ could be practically utilized. Since the early 1980 s, wind power has become one way of electricity supply in rural areas. After 20 years of development, the $1 \mathrm{~kW}$ wind turbine technology has matured and the annual sales reach 6,000 to 8,000 generators. Till the end of 2001, twenty-eight large wind farms have been built in China with 814 wind turbine generators and an installed capacity of $401,095 \mathrm{~kW}$, and are mainly distributed in Xinjiang and Inner Mongolia Autonomous Regions (He, 2007). West China is characterized by vast area and sparse population, with abundant wind resources, such as Hexi Corridor in the Gansu province, Inner Mongolia Autonomous Region, and Dabancheng in the Xinjiang Autonomous Region, and construction of large wind farms in these places would bring great benefits by conversion and utilization of wind energy.

For the utilization of wind energy, regional development strategy of wind energy should be made according to the distribution of wind resources, and wind energy conversion equipment should be innovated and the cost of popularization and utilization of wind energy should be reduced, so that the development of wind energy could be achieved.

2) Strategy for solar energy development in Qinghai-

\section{Tibet Plateau}

The solar energy received on the land surface of China is estimated to be $5.0 \times 10^{19} \mathrm{~kJ} / \mathrm{year}$ and the annual solar energy is about $335-837 \mathrm{~kJ} / \mathrm{cm}^{2} \cdot a$. The Qinghai-Tibet Plateau and the northwest China have the most abundant solar energy resources. The Qinghai-Tibet Plateau with an altitude more than $4,000 \mathrm{~m}$ and rarefied air and good air cleanness, is the intensive solar energy region characterized by annual sunshine duration of 3,200-3,300 $\mathrm{h}$ and solar energy of $6.70 \times$ $10^{6}-8.37 \times 10^{6} \mathrm{~kJ} / \mathrm{cm}^{2} \cdot \mathrm{a}$, which equals to the energy emitted by burning 225-285 kg standard coal. The Qinghai-Tibet Plateau 
is a very suitable place for large solar energy conversion programs.

So far there are three kinds of solar energy utilization, i.e. solar water heater, solar cooker and solar photoelectric cell, all of which are utilized in a relatively small scale. Large scale utilization of solar photovoltaic power systems is not praetical due to the high cost and the lack of market competitiveness. So construction of large solar energy photovoltaic power station in the Qinghai-Tibet Plateau on the basis of technical innovation has strategic significance for resolving the problems of energy shortage and environmental pollution in China.

\section{3) Strategy for biomass energy development}

Compared with solar energy, wind energy and tidal power, bio-energy is the most popular clean energy in technology level and popularization level, especially the technical innovation of methane fermentation equipment makes it possible to use agricultural wastes as resources. The strategy for biomass energy development is suggested as follows:

\section{Comprehensive utilization of agricultural wastes}

A lot of crop straw, livestock and poultry manure, organic domestic wastes and human excrement are generated in the process of agricultural activities. It was estimated that in $2003,7.097 \times 10^{8} \mathrm{t}$ of crop straw, $4.521 \times 10^{9} \mathrm{t}$ of livestock and poultry manure and $2.454 \times 10^{4} \mathrm{t}$ of human excrement were generated, which would not only pollute the rural environment but also cause great waste of resource if it was not utilized properly. Comprehensive utilization of agricultural wastes is not a present issue but an ancient fact, even now these agricultural wastes are still used to provide people with lots of livelihood energy in many places in different utilization modes and levels from those in ancient time. The conventional utilization way of agricultural wastes is direct combustion, which is simple but not efficient. This method is basically used in small production scale and low productivity level, but with the industrialization of agriculture and increase in productivity, its disadvantages become more and more evident. Firstly, the utilization efficiency of agricultural wastes is low that can not meet the size of wastes generation. Secondly, the low utilization efficiency can cause a secondary waste of resource. Thirdly, it is difficult to directly utilize livestock and poultry manure and human excrement. Therefore, it is necessary to make a new strategy for utilization of agricultural wastes.

Methane fermentation is a relatively mature utilization mode of agricultural wastes, the main purpose of which is to decompose agricultural and livelihood wastes, such as livestock and poultry manure to provide energy for rural population. The utilization of methane fermentation would be planned based on different agricultural wastes, climates, production modes and life styles in different regions in order to guarantee its ecological, economic and social benefits. At the same time other modes and technologies for utilizing agricultural wastes, such as technology for gasification of crop straw and technology for high density biomass energy, should be developed.

Strategy for energy-oriented-agriculture

Energy-oriented-agriculture means the agricultural activities with which solar energy is converted into organic energy by green crops through the photosynthesis process and then transformed to energy that can be used directly under certain technical conditions. As an earliest industry, agriculture provides not only food and clothing for people but also plenty of energy in the long historical process. Even now agriculture is still the main energy source in many places especially in rural areas of developing countries. In 1991, the crop straw used as energy in China was equivalent to $1.64 \times 10^{8} \mathrm{t}$ of standard coal and, in 1995 and 1996, that was equivalent to $1.59 \times 10^{8} \mathrm{t}$ and $1.20 \times 10^{8} \mathrm{t}$ of standard coal, respectively, which accounted for $16.35 \%, 12 \%$ and $8.96 \%$ of the annual energy consumption, respectively.

From the point of view of technology system, energyoriented-agriculture consists of many aspects related to agriculture and energy. From the perspective of raw material source, the technology system of energy-orientedagriculture includes technologies of planting energy plants, energy-oriented livestock husbandry, energy forestry and processing of energy-oriented-agriculture, and can be further divided into animal resource and plant resource. The processing technologies of energy-oriented-agriculture mainly include extraction and processing of animal fat from animal resources, and extraction and processing of vegetable oil, carbohydrate and starch from plant resources, and technologies of converting these resources into fuels such as ethanol, bio-diesel and methane (Yang et al, 2005; Feng and Yang, 2006; Feng et al, 2005a).

Within the constrains of food security and the background of environmental restoration and remediation in west China, through combination of ecological construction and plantation of energy plants, the problem of energy shortage in China might be improved by agricultural production, for example, plantation of energy plants in a large scale (Li, 2004).

\subsection{Scientific and technical support for clean energy development in China}

Scientific and technical support is an important part of national energy strategy of China. Based on the abovementioned strategy for clean energy development, the scientific and technical support system for clean energy development in the coming years could consist of the following aspects:

3.2.1 Clean utilization technology and utilization mode of conventional energy

The emission of pollutants such as $\mathrm{CO}_{2}, \mathrm{NO}_{x}, \mathrm{SO}_{2}$ and dust is inevitable during the combustion of coal, oil and natural gas. Technologies and practices for cleaner utilization of conventional energy must be developed to reduce these harmful emission.

3.2.2 Innovation in technology and equipment for utilization of wind energy and solar energy in large scale and at low cost

So far most of key technologies and equipment used in wind energy and solar energy in China are imported, the cost of which is so high that it is difficult to popularize. The research of wind energy and solar energy should be focused on the following aspects.

- Key technology of solar electricity generation; 
- Solar energy heating and cooling technologies;

- Technical innovation of solar water heating systems;

- Solar photovoltaic technology;

- Conversion of solar energy to chemical energy;

- Key technology of large capacity wind turbine generators and manufacture of equipment;

- Technology of wind power generation at low wind speed and manufacture of equipment;

- Technology of offshore wind power generation;

- Technology of new materials for solar energy conversion.

\subsubsection{Biomass energy conversion technology}

Technology support of biomass energy includes the technologies of methane fermentation with high efficiency and large-size methane projects, and bio-diesel and fuel ethanol, and related conversion devices and equipment.

1) Efficient methane fermentation and microbes regulation

As a relatively mature technology, methane fermentation has already been popularized in China, but further development is hindered by the Lack of such fundamental research as efficient methane generation mechanisms, separation of anaerobic microbe strains, and breeding and utilization technologies of anaerobic microbe strains. The purpose of fundamental research of efficient methane fermentation is to make clear the fermentation flora and the best threshold value of fermentation microbes, to select and identify the valuable methane generating strains, to make clear the pretreatment agent for crops straw fermentation, and the different combined microbial agents of functional bacterial strains and related production technology, and to support the energy utilization of agricultural wastes in both theory and technology.

2) Technology support for development of bio-diesel

Bio-diesel, an alternate for conventional diesel fuel, is a long-chain fatty acid methyl (or ethyl) ester produced through an exchange reaction of animal fat (or vegetable oil) with methanol or ethanol. The main raw materials for bio-diesel production are all kinds of natural vegetable oils such as soybean, rapeseed and palm oil, even waste cooking oil. The technologies for bio-diesel production include:

- Technology for directional breeding and cultivation of germplasm resources of high-oil crops;

- Technology for breeding and cultivation of energy plants;

- Technology for vegetable oil conversion;

- Technology for refining and conversion of cooking waste oil.

\section{3) Technology for fuel ethanol production}

Compared with other technologies for bio-mass energies, the technology for fuel ethanol is relatively mature and fuel ethanol has already entered the market as vehicle fuel, but the shortage of raw material limits its further development. The main raw material for fuel ethanol production is crops seed with a high content of starch, so food security is the precondition for development of fuel ethanol. The most important measure for development of fuel ethanol is to breed some crop varieties with a high content of starch under the pre-condition of food security.

In the above technology support system of clean energy in China, the design and manufacture of conversion equipment directly limit the development of technologies. So the manufacture and installation of conversion equipment for clean energy is the core of the technology support system.

\subsection{Policy and laws support for clean energy development in China}

When conversion efficiency and investment cost are concerned, clean energy has no price advantage compared with conventional energy. It is necessary for the government to provide policy and laws supporting this new, infant industry.

\subsubsection{Policy support for clean energy development}

The service and guarantee function of policies in the implementation of energy strategy in the 21st century should be brought into play in order to promote the development of energy, and the research of energy policy and financial support should also be strengthened, and the experiences and achievements of foreign energy policies should be used for reference. In China, the energy policy could be established and promoted in the following aspects (Wang et al, 2006).

\section{1) Financial subsidy mechanism}

In the USA, Brazil and European countries, there exists a financial subsidy mechanism for clean energy since it has no price advantages in technologies and conversion equipment compared with conventional energy. In the research and popularization processes of clean energy, financial and policy supports could be provided to related companies and research institutions to smooth the way for the application and popularization of clean energy.

2) Revenue relief system

Supporting the clean energy development through tax revenue is a widely used policy in the world, because the tax incentive for clean energy producers and users can significantly promote the development of clean energy. Although clean energy has no cost advantage compared with conventional energy, it has an evident effect on reduction of greenhouse gas emission, so the government should encourage investments and human resources to come into this field through revenue relief policy. For example, the USA carried out a 3,400 dollars tax incentive policy per car to encourage purchasing of hybrid vehicles and clean diesel vehicles with the purpose of reducing market demands for gasoline.

\subsubsection{Laws support for clean energy development}

Promoting clean energy development through legislation is a widely adopted measure in foreign countries whether by government purchase or by market stimulation. The Public Power Regulatory Policies Act of the US was enacted in 1978 to encourage power companies to purchase renewable energy power and plenty of power purchasing contracts were signed between power generation companies and power suppliers with the grid electricity price higher than 0.1 US dollar per $\mathrm{kWh}$. Although the beginning of renewable energy development in Britain was late, the Non-Fossil Fuel Obligation (NFFO) promoted a stable development of 
renewable energy. In 1998, the Netherlands issued a new power act with a Green Certificate Program which stipulated in detail that every consumer had an obligation to purchase green power at a minimum limit. The Feed-in law of Germany passed in 1991 forced power companies to purchase renewable power, and in 1998, a supplement was made to it, with an upper limit set to the purchase of renewable power, that is, no more than $5 \%$ of total power consumption in power networks areas. On April 1, 2004, an Act on Granting Priority to Renewable Energy was started in Germany, which required power companies to preferentially purchase renewable power at a fixed price before traditional power. In 1997, Japan implemented the Bill of Special Measures for Utilization of New Energy. The clean energy in foreign countries has been developed significantly through legislation (Energy Research Institute, 2006; Wang and Shi, 2003; Shi, 2006). The Law of Renewable Energy passed in 2006 in China is a powerful legal guarantee and has played an important role in the development of clean energy. So in the long term, the law enforcement needs to be improved in order to ensure that the laws are strictly obeyed. The detailed regulations of some laws also need to be improved for better implementation.

\section{Conclusions}

Environmental problems caused by increasing global warming together with the uncertain security of conventional energy are the background of clean energy development. Clean energy is not a simple classification of energy resources, but involves technical issues concerning environmentally friendly aspects during energy utilization. The establishment of a strategic framework for clean energy development at the level of development strategy, technology support and policy and law support is important in maximizing energy security and ecological safety, as well as the sustainable development of economy and society.

\section{References}

Energy Research Institute/NDRC, P. R. China, Promoting the development of China's renewable energy by adopting foreign experiences in legislation. http://www.hwcc.com.cn. December 31, 2006 (in Chinese)

Feng Y Z and Yang G H. Technological system construction of China's energy agriculture. Journal of Northwest Sci-Tech University of Agriculture and Forestry. 2006. 1: 30-34 (in Chinese)

Feng Y Z, Yang G H, Ren G X, et al. Necessity and strategy of development of energy-oriented-agriculture in China. Chinese Agricultural Science Bulletin. 2005a. 21(4): 344-347 (in Chinese)

Feng Y Z, Yang S Q, Ren G X et al. Opportunity and challenge of biogas industry under the double background of environment and energy problems. China Biogas. 2005b. 23 (3): 33-34, 43 (in Chinese)

He L Q. The Using status quo of wind energy. Taiyuan Science \& Technology. 2007. (11): 17-18 (in Chinese)

Li D J. Developing sweet sorghum industry to resolve the problems of food and energy security and agriculture in China. Review of China Agricultural Science and Technology. 2004. (5): 55-58 (in Chinese)

Pan J Z. Energy source and policy in China. Nature Magazine. 1997. 19(5): 249-254 (in Chinese)

Shi J L. The trend and prospect of renewable power in the world. Energy of China. 2006. 28(11): 26-29 (in Chinese)

Su Y X, Mao Y R and Zhao D J. New Energy and Renewable Energy. 2006. Beijing: Chemical Industry Press (in Chinese)

Wang D Q, Qin S Q and Wu W Y. Establishment of system on renewable energy resources development in China. Journal of Jiangxi Normal University (Philosophy and Social Sciences Edition). 2006. 39(6): 15-19 (in Chinese)

Wang X J and Shi F J. The utilization of renewable energy in Europe. Journal of Hebei Institute of Architectural Engineering. 2003. 21(3): 79-86 (in Chinese)

Yang X N, Feng Y Z and Ren G X. Characteristics of energy supply and consumption and analysis of the strategies to solve these problems in China. Journal of Northwest Sci-Tech University of Agriculture and Forestry. 2005. (5): 152-155 (in Chinese)

Yu S Q. Clean energy and its efficient utilization. Shanghai Energy Conservation. 2006. (6): 36-38 (in Chinese)

Yuan Z H, Wu C Z and Ma Z L. Theories and technologies of biomass utilization. 2005. Beijing: Chemical Industry Press (in Chinese)

Zhai X J, Liu K R and Han Q. Technologies of new energy. 2005. Beijing: Chemical Industry Press (in Chinese)

Zhang G B. Making good use of water potentials to provide human being with sustainable clean energy. Water Power. 2004. 301(12): 3-5 (in Chinese)

(Edited by Zhu Xiuqin) 